\title{
Formation of Halogenated C-, N-DBPs from Chlor(am)ination and UV Irradiation of Tyrosine in Drinking Water
}

\author{
Wenhai Chu ${ }^{\text {a }}$, Naiyun Gao a, ${ }^{\mathrm{*}}$, Stuart W. Krasner ${ }^{\mathrm{b}}$, Michael R Templeton ${ }^{\mathrm{c}}$, Daqiang Yin $^{\mathrm{a}}$ \\ ${ }^{a}$ State Key Laboratory of Pollution Control and Resources Reuse, College of \\ Environmental Science and Engineering, Tongji University, Shanghai, 200092, China \\ ${ }^{\mathrm{b}}$ Metropolitan Water District of Southern California, 700 Moreno Avenue, La Verne, \\ California 91750-3399, USA \\ 'Department of Civil and Environmental Engineering, Imperial College London, London, \\ SW7 2AZ, UK
}

${ }^{*}$ Corresponding author.

Address: State Key Laboratory of Pollution Control and Resources Reuse, Tongji University, Mingjing Building No. 601, 1239 Siping Road, Yangpu District, Shanghai, 200092, China

Tel: +862165982691

Fax: +862165986839

E-mail: feedwater@yahoo.cn, feedwater@126.com.

\section{Abbreviations:}

Alanine -Ala; aspartic acid -Asp; carbonaceous disinfection by-products -C-DBPs; chloroform -CF; chloral hydrate - $\mathrm{CH}$; 4-chlorophenol -4-CP; cyanogen chloride - $\mathrm{CNCl}$; 1,1-dichloropropanone -1,1-DCP; disinfection by-products -DBPs; dichloroacetic acid -DCAA; dichloroacetamide -DCAcAm; dichloroacetonitrile -DCAN; dichloromethane -DCM; 2,4-dichlorophenol-2,4-DCP; dissolved organic carbon - DOC; dissolved organic nitrogen - DON; gas chromatography/mass spectrometry -GC/MS; haloacetic acids HAAs; haloacetamides -HAcAms; haloacetonitriles -HANs; halonitromethanes -HNMs; 4-hydroxy-benzyl-cyanide -4-HBC; nitrogenous disinfection by-products- N-DBPs; natural organic matter - NOM; purge \& trap- P\&T; trichloroacetic acid -TCAA; trichloroacetyl chloride -TCAC; trichloroacetamide -TCAcAm; trichloroacetonitrile -TCAN; trichloronitromethane-TCNM; 2,4,6-trichlorophenol-2,4,6-TCP; 1,1,1-trichloropropanone -1,1,1-TCP; trihalomethanes -THMs; tyrosine -Tyr; U.S. Environmental Protection Agency -USEPA; water treatment plants-WTPs. 


\section{Abstract}

The formation of regulated and emerging halogenated carbonaceous (C-) and nitrogenous disinfection by-products (N-DBPs) from the chlor(am)ination, UV irradiation of tyrosine (Tyr) was investigated. Increased chlorine contact time and/or $\mathrm{Cl}_{2} / \mathrm{Tyr}$ ratio increased the formation of most C-DBPs. In contrast, 4-chlorophenol, dichloroacetonitrile, and dichloroacetamide had their greatest yields at particular conditions. Chloroform and dichloroacetic acid increased with increasing $\mathrm{pH}$, dichloroacetonitrile first increased and then decreased, and other DBPs had maximum yields at $\mathrm{pH} 7$ or 8 . The addition of ammonia significantly reduced most C-DBPs formation but increased 4-chlorophenol, dichloroacetonitrile, dichloroacetamide, and trichloroacetonitrile yields for short pre-chlorination contact times before dosing ammonia. When UV irradiation and chlorination were performed simultaneously, the relatively stable C-DBPs increased, and dichloroacetonitrile, dichloroacetamide, and 4-chlorophenol decreased with increasing UV dose. This information was used to develop a mechanistic model for the formation of intermediate DBPs and endproducts from the interaction of disinfectants with tyrosine.

\section{Capsule abstract}

Exploring the integrated formation mechanism of regulated and emerging highly toxic DBPs, which is expected to preferably reduce their occurrence in drinking water.

Keywords: Drinking water; Nitrogenous disinfection by-products; Tyrosine; Haloacetamides; Halonitromethanes; Integrated formation pathway 


\section{Introduction}

Currently, water resource shortages and growing water demands have spurred utilities to exploit source waters impaired by treated wastewater effluents and/or algal blooms. Such source waters are typically characterized by higher dissolved organic nitrogen (DON) levels, where amino acids constitute an important class of the DON pool and may account for $15 \%$ and $35 \%$ of the DON (Westerhoff et al., 2002). During chlorination or chloramination, components of the DON in water can react with the disinfectant to form halogenated nitrogenous disinfection by-products (N-DBPs), such as haloacetamides (HAcAms), halonitromethanes (HNMs) and haloacetonitriles (HANs) (Richardson et al., 2007), which represent an emerging concern due to their cytotoxicity and genotoxicity (Plewa et al., 2004; Muellner et al., 2007; Richardson et al., 2011). In particular, haloacetamides (HAcAms), an emerging class of halogenated N-DBPs that have been measured in tap waters (Krasner et al., 2006), exhibited much higher genotoxicity and cytotoxicity than many C-DBPs (e.g., trihalomethanes [THMs] and haloacetic acids [HAAs]) (Plewa et al., 2008).

Most formation studies, based on model compounds such as free amino acids, focus on C-DBPs (e.g., THMs and HAAs) and certain N-DBPs (HANs), relatively little involved HAcAms and HNMs. Some laboratory studies reported that aromatic amino acids (e.g., tyrosine [Tyr]) generally produced more chloroform (CF) and other THMs than non-aromatic ones, and amino acids with a ring structure (e.g., Tyr) resulted in higher yields of dichloro- (DCAA) and trichloroacetic acid (TCAA) during chlorination (Hong et al., 2009). Chlorination (oxidation) of certain amino acids (e.g., Tyr, tryptophan, aspartic acid 
[Asp]) can result in the formation of aldehydes and nitriles, with subsequent or concomitant chlorine substitution to form trichloroacetaldehyde (chloral hydrate $[\mathrm{CH}]$ ) and dichloroacetonitrile (DCAN), respectively (Trehy et al., 1986), whereas other amino acids (e.g., glycine, alanine, serine) did not (Trehy and Bieber, 1981). Recently, selected amino acids were shown to react with chlorine to form other N-DBPs, such as cyanogen chloride (CNCl) in the case of glycine ( $\mathrm{Na}$ and Olson, 2006) and trichloronitromethane (TCNM) in the case of Asp (Hu et al., 2010). For HAcAms, there is only one study that assessed the role of amino acids in the formation of dichloroacetamide (DCAcAm) (Chu et al., 2010b), the most common HAcAm formed in chlorinated and chloraminated drinking water (Krasner et al., 2006), and found that Asp, histidine, and Tyr had the highest DCAcAm yields among 20 free amino acids.

In these studies on DBP formation during chlorination of amino acids, Tyr was a typical precursor for certain C- and N-DBPs. Moreover, Tyr is a naturally occurring amino acid present in many peptides, proteins, and algae (Ram, 1985; Szajdak and Österberg, 1996). Mitch et al (2009) investigated the occurrence of amino acids in some US water treatment plants (WTPs)influent samples, and found the maximum concentration of hydrolyzable Tyr reached $27.4 \mu \mathrm{g} / \mathrm{L}$ (average $=9.0 \mu \mathrm{g} / \mathrm{L}$ ). In practical WTPs, pre- or post-chlor(am)ination may caused the formation of multiple DBPs from Tyr and other compounds (e.g., proteins, algae, humics) containing Tyr. Pre-chlor(am)ination is a common practice in China now to reduce tastes, odors, and algal growths. Although the above-mentioned studies reported the formation of individual DBP species from the chlorination of Tyr, a comprehensive reaction scheme, which includes key intermediates resulting in multiple DBP formation, is 
lacking to date. Also, a novel possible pathway for the emerging HAcAms formation was proposed in the present study, which updated the previous speculation that HAcAms was from the hydrolysis of HANs. Besides, chloramination in practice often does not involve adding preformed chloramines, but rather adding ammonia and chlorine. The order of addition and/or free chlorine contact time can impact DBP formation during post-chloramination (Schreiber and Mitch 2009). Especially, the results for the formation of some emerging N-DBPs (e.g., DCAcAm, trichloroacetamide [TCAcAm]) during certain free chlorine contact times before adding ammonia were still lacking. Moreover, UV treatment is an emerging disinfection process for drinking water, and transformation of the NOM by UV irradiation could change the formation of some DBPs during post-chlorination (Liu et al., 2006; Dotson et al., 2010; Reckhow et al., 2010). At present, the contribution of UV irradiation on multiple DBP (esp. HAcAms) formation from selected individual amino acids is unknown.

A better understanding of the comprehensive formation mechanism of $\mathrm{C}$ - and N-DBPs during disinfection may improve the accuracy of predicting DBP occurrence and make it possible to optimize disinfection practices that minimize the formation of C- and N-DBPs. The objective of this study was to assess the role of Tyr in the formation of multiple chlorinated C- and N-DBPs: CF, DCAA, TCAA, 1,1-dichloro-2-propanone (1,1-DCP), 1,1,1-trichloropropanone (1,1,1-TCP), CH, DCAN, trichloroacetonitrile (TCAN), TCNM, DCAcAm, TCAcAm, $\mathrm{CNCl}$, and 4-chlorophenol (4-CP). This was evaluated for chlorination with and without UV irradiation and for chloramination under various conditions. Moreover, an important goal was to explore the formation pathways of these 
C- and N-DBPs, which is expected to contribute to a better understanding and prediction of the control and formation of these DBPs.

\section{Materials and methods}

\subsection{Materials}

THMs (Supelco 47904), HAAs (Supelco 49107-U), 4-CP (Supelco 48689), and CH (47335-U) chemical standards, and EPA 551B standard mixture (Supelco 48046) containing DCAN, TCAN, 1,1-DCP, 1,1,1-TCP, and TCNM were purchased from Sigma-Aldrich (St. Louis, Missouri, USA). Tyr (98.5\%) was obtained from Wako (Osaka, Japan). DCAcAm (98.5\%) and TCAcAm (99\%) were obtained from Alfa Aesar (Karlsruhe, Germany). The extraction solvent ethyl acetate was obtained from Fisher Scientific (Waltham, Massachusetts, USA). Guaranteed reagent (GR) grade reagents-sodium hypochlorite $(\mathrm{NaOCl})$, sodium hydroxide $(\mathrm{NaOH})$, hydrochloric acid $(\mathrm{HCl})$, ammonium chloride, sodium nitrite, sodium nitrate, buffer salts, glacial acetic acid, ascorbic acid, and anhydrous sodium sulfate-were purchased from Sinopharm Chemical Reagent Co., Ltd. (Shanghai, China). All solutions were prepared using ultrapure water produced with a Millipore Milli-Q Gradient water purification system (Billerica, Massachusetts, USA). All bottles were prewashed with phosphate-free detergent, rinsed with ultrapure water, and dried in an oven at $105^{\circ} \mathrm{C}$ for $24 \mathrm{~h}$. Chlorine solutions were prepared by diluting a $6 \%$ $\mathrm{NaOCl}$ solution with ultrapure water, which was standardized daily prior to use.

\subsection{Disinfection experiments}

Chlorination and chloramination experiments were conducted at a controlled room 
temperature $\left(23.0 \pm 0.2^{\circ} \mathrm{C}\right)$ and under headspace-free conditions in $200-\mathrm{mL}$ brown glass volumetric flasks, which were kept in the dark. During chlorination experiments, a typical run involved applying a certain chlorine dose $(0.5,1.5,2.5 \mathrm{mM})$ to a Tyr solution $(0.1 \mathrm{mM})$ for the designated reaction time. To stop the chlorination reaction, the disinfectant residual was quenched with ascorbic acid with a normality twice as high as the initial normality of the chlorine added, because ascorbic acid has little effect in the stability and analysis of these investigated halogenated N-DBPs and C-DBPs (Joo and Mitch, 2007; Chu et al., 2009a). $\mathrm{NaOH}$ and $\mathrm{HCl}$ were used to adjust the solution $\mathrm{pH}$ value $(\mathrm{pH}=5 \sim 9)$. Buffer solutions were prepared from phosphate and carbonate salts. For comparing the effect of chloramination on DBP formation, certain amounts of ammonium chloride were added to provide ammonia at the desired level. By adjusting the free chlorine contact time before dosing ammonia, three chloramination schemes were examined: I. Chloramination with preformed monochloramine, where ammonia and chlorine with the same molar concentration were dosed to the Tyr solution. II. Prechlorination (1-h), where ammonium chloride with the same molar concentration as the residual chlorine after $1 \mathrm{~h}$ was added to a Tyr solution pre-chlorinated for 1 h. III. Prechlorination (6-h), where ammonium chloride with the same molar concentration as the residual chlorine after $6 \mathrm{~h}$ was added to a Tyr solution pre-chlorinated for $6 \mathrm{~h}$. In order to examine the effect of UV irradiation on the formation of DBPs during chlorination of Tyr, before chlorination disinfection or at the same time, some water samples were irradiated in a low pressure UV reactor with different UV doses from 19.5 to $585 \mathrm{~mJ} / \mathrm{cm}^{2}$, as shown in Supplementary Information (SI) (Figure SI and Table S1). 


\subsection{Analytical Methods}

A UV/Vis double-beam spectrophotometer (Unico4802, Dayton, New Jersey, USA) was used to scan the spectrum of different samples from 220 to $500 \mathrm{~nm}$ at $10-\mathrm{nm}$ intervals. Residual and total chlorine were detected by a portable spectrophotometer $(\mathrm{HACH}$ DR2800) based on HACH method 8021. Prior to DBP analysis, glacial acetic acid was used to lower the $\mathrm{pH}$ to $4.8-5.5$ for the THM, HAN, and TCNM samples, and to $5.0 \pm 0.2$ for the HAcAm samples to prevent base-catalyzed hydrolysis of HANs or HAcAms (Chu et al., 2009a). CF, CH, DCAN, TCAN, TCNM, 1,1-DCP, and 1,1,1-TCP were measured using purge \& trap (P\&T) (OI Analytical, Eclipse 4660, College Station, Texas, USA) and gas chromatography/mass spectrometry (GC/MS) (Shimadzu-QP2010, Kyoto, Japan), based on the U.S. Environmental Protection Agency (USEPA) Method 524.2. Two HAAs (DCAA and TCAA) were measured by GC (Shimadzu-QP2010) with an electron capture detector, based on USEPA Method 552.2 (Gao et al., 2009). DCAcAm and TCAcAm were analyzed using liquid-liquid extraction and GC/MS (Shimadzu-QP2010). The analysis details of DCAcAm and TCAcAm are available elsewhere (Chu et al., 2010b). Additionally, the details of the 4-CP analysis are briefly described in the SI. This study did not quantify the concentration of $\mathrm{CNCl}$ or dichloromethane (DCM), but they were examined qualitatively by P\&T and GC/MS (Figure S3). The same was done for trichloroacetyl chloride (TCAC). The yield of each DBP was calculated by the molar ratio of the formed DBP to the initial concentration of Tyr (Eq. S1).

\section{Results and Discussion}




\subsection{Time-dependent formation of DBPs from Tyr}

[Fig.1]

Figures $1 \mathrm{~A}$ and $\mathrm{B}$ show the time-dependent formation of $\mathrm{C}$ - and N-DBPs during chlorination of tyrosine at $\mathrm{a} \mathrm{Cl}_{2} / \mathrm{Tyr}$ molar ratio of 15 at $\mathrm{pH}$ 7. There was a free chlorine residual at all times tested at $\mathrm{Cl}_{2} / \mathrm{Tyr}=15$ (Figure S4) because the chlorine demand was approximately $13 \mathrm{~mol} \mathrm{Cl}_{2} / \mathrm{mol}$ Tyr. As shown in Table S2, at $\mathrm{Cl}_{2} / \mathrm{Tyr}=15$ (as well as at 5 or 25), 1,1-DCP, 1,1,1-TCP, and TCACAm were not detected, and the yields of TCAN and TCNM were lower than $0.02 \%$, which were too low to distinguish a notable difference. From Figures $1 \mathrm{~A}$ and $\mathrm{B}\left(\mathrm{Cl}_{2} / \mathrm{Tyr}=15\right)$, the yields of $4-\mathrm{CP}(2.8 \%)$ and DCAN $(1.6 \%)$ were much higher than other tested DBPs at the first $1 \mathrm{~h}$, and they gradually decreased by 168 $\mathrm{h}$ to $0.05 \%$ and $0.11 \%$, respectively. (Their half-lives were $>6$ and $<6 \mathrm{~h}$, respectively.) The concentrations of four detected C-DBPs (CF, DCAA, TCAA, and $\mathrm{CH}$ ) increased with increasing contact time and maximized at 4.0, 2.4, 2.9 and $0.46 \%$ at $168 \mathrm{~h}$. The yield of the relatively unstable N-DBP DCAcAm (Chu et al., 2009a) peaked at $0.16 \%$ at $6 \mathrm{~h}$, and then declined at higher contact times (down to $0.05 \%$ at $168 \mathrm{~h}$ ).

CF, DCAA, and TCAA were relatively stable in the presence of chlorine and generally were the endproducts of chlorination of Tyr in the absence of bromide. $\mathrm{CH}$ can form CF by base-catalyzed hydrolysis under alkaline conditions (Chu et al., 2009b), but the hydrolysis rate of $\mathrm{CH}$ is lower than the corresponding formation rate in neutral solution. The trends of DCAcAm formation and degradation can be explained by the hydrolysis of DCAN and DCAcAm. DCAN can hydrolyze to form DCAcAm (e.g., from 1 to $6 \mathrm{~h}$ ), and DCAcAm can further hydrolyze to produce DCAA (e.g., after 6 h) (Table S3, Eq. S2) (Glezer et al., 1999; 
Reckhow et al., 2001; Chu et al., 2009b; Chu et al., 2010a). Note that the loss of DCAN cannot be fully accounted for by the increases in formation of DCAcAm or DCAA.

\subsection{Effect of chlorine dosage}

The yields of C- and N-DBPs after a 24-h chlorination of Tyr at different $\mathrm{Cl}_{2} /$ Tyr ratios are shown in Figures $1 \mathrm{C}$ and D. Four relatively stable C-DBPs (CF, DCAA, TCAA, CH) increased with increasing $\mathrm{Cl}_{2} / \mathrm{Tyr}$, whereas $4-\mathrm{CP}$ decreased with increasing $\mathrm{Cl}_{2} / \mathrm{Tyr}$. The yields of some N-DBPs (DCAN and DCAcAm) reached their highest levels at $\mathrm{Cl}_{2} / \mathrm{Tyr}=15$. $\mathrm{At}_{\mathrm{Cl}} / \mathrm{Tyr}=5$, residual chlorine was barely detected at $0.02 \mathrm{mg} / \mathrm{L}$ detection limit (Figure

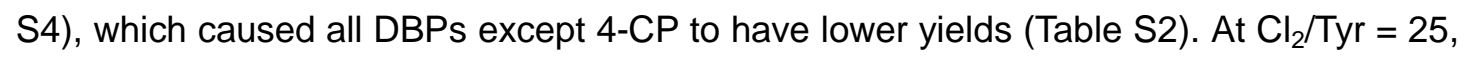
the excess chlorine accelerated the decomposition rate of DCAN (Reckhow et al., 2001), whereas DCAcAm was similar to what was present at $\mathrm{Cl}_{2} / \mathrm{Tyr}=15 . \mathrm{CNCl}$ and $\mathrm{DCM}$ were detected at $\mathrm{Cl}_{2} / \mathrm{Tyr}=5$. There was no significant change in $\mathrm{CNCl}$ level formed at different chlorine contact times, whereas the DCM peak area gradually decreased with increasing contact time (Figure S3). Na and Olson (2006) demonstrated that the chlorination of glycine could form $\mathrm{CNCl}$, where higher chlorine concentrations promoted its hydrolysis. The absence of $\mathrm{CNCl}$ during chlorination of $\mathrm{Tyr}$ at $\mathrm{Cl}_{2} / \mathrm{Tyr}=15$ or 25 was most likely due to hydrolytic degradation of the $\mathrm{CNCl}$ by the free chlorine.

\subsection{Effect of $\mathrm{pH}$}

\section{[Fig.2]}

The yields of C- and N-DBPs upon 24-h chlorination of Tyr at different pH levels are summarized in Figures $2 \mathrm{~A}$ and $\mathrm{B}$, respectively. As shown, CF and DCAA yields kept growing with increasing $\mathrm{pH}$ from 5 to 9 . However, during the chlorination of humic acid, 
increase in $\mathrm{pH}$ increases $\mathrm{CF}$ formation, but decreases DCAA formation (Babcock and Singer, 1979). The impact of $\mathrm{pH}$ (e.g., from 7 to 9) was higher for $\mathrm{CF}$ (yield at $\mathrm{pH} 9$ was $147 \%$ higher than yield at $\mathrm{pH} 7$ ) than for DCAA (yield at $\mathrm{pH} 9$ was $124 \%$ higher than yield at $\mathrm{pH}$ 7). DCAN reached a maximum yield of $2.4 \%$ at $\mathrm{pH}=6$ and dropped substantially (to a $0.35 \%$ yield) at $\mathrm{pH} 7$. The highest formation of TCAA, $\mathrm{CH}$, and DCAcAm occurred at $\mathrm{pH}$ 7 to 8 , which had maximum yields of $0.76-0.78,0.18-0.24$, and $0.12-0.14 \%$, respectively. However, 4-CP yields (0.59 to $0.74 \%$ ) were relatively insensitive to $\mathrm{pH}$. At different $\mathrm{pH}$ levels, chlorination of Tyr was not able to produce sufficient TCNM to make notable differences. TCAN gave low yields at $\mathrm{pH} 5$ to 8 and was not detected at $\mathrm{pH} 9$, and TCAcAm was not detected at all.

The effect of $\mathrm{pH}$ on the DBP yields is mainly attributable to their stability and formation pathway from Tyr. Many of these results are consistent with previous research in bulk water (e.g., conducted at $\mathrm{pH}$ levels of 5, 7, and 9.4) that has shown CF formation increasing with $\mathrm{pH}$; whereas $\mathrm{CH}$ formation increased over time at $\mathrm{pH} 5$ and 7 , and $\mathrm{CH}$ that had formed within $4 \mathrm{~h}$ at $\mathrm{pH} 9.4$ decayed over time at the elevated $\mathrm{pH}$; and DCAN formation only increased over time at $\mathrm{pH} 5$, while DCAN formed within $4 \mathrm{~h}$ at $\mathrm{pH} 7$ decayed over time at the neutral $\mathrm{pH}$, and DCAN formed to a low extent at all reaction times at pH 9.4 (Stevens et al., 1989). Relatively stable CH and TCAA, and relatively unstable TCAN, DCAN, and DCAcAm are also all easily hydrolyzed to CF or DCAA under alkaline conditions (Yang et al., 2007; Chu et al., 2009b). The incremental increase in DCAA under alkaline conditions was due in part to the hydrolysis of DCAN and DCAcAm. As shown in Table S4, with $\mathrm{pH}$ increasing from 7 to 9 , the sum of the losses of DCAN and 
DCAcAm (0.41\%) was greater than the increase in DCAA $(0.17 \%)$. Alternatively, the sum of the losses of TCAA, $\mathrm{CH}$, and TCAN $(0.089 \%)$ was far lower than the increase in CF $(0.52 \%)$. Therefore, there are other reasons to cause the incremental increase in CF rather than only the hydrolysis of TCAA, $\mathrm{CH}$, and TCAN. For example, the alkaline environment can facilitate the rapid opening of the benzene ring, which can promote the formation of CF (Chu et al., 2009c)

Apparent first-order rate constants for the decomposition of DCAN in the presence or absence of chlorine were $1.8 \times 10^{-5} \mathrm{~s}^{-1}$ (initial free chlorine was $10 \mathrm{mg} / \mathrm{L}, \mathrm{pH}=7.0$ ) and 7.5 $\times 10^{-7} \mathrm{~s}^{-1}(\mathrm{pH}=7.5)$ (Reckhow et al., 2001; Yang et al., 2007). These were higher than the apparent first-order rate constants for the decomposition of DCAcAm, which were $4.55 \times$ $10^{-6} \mathrm{~s}^{-1}$ (initial free chlorine was $\left.10 \mathrm{mg} / \mathrm{L}, \mathrm{pH}=7.0\right)$ and $2.37 \times 10^{-7} \mathrm{~s}^{-1}(\mathrm{pH}=7.5)(\mathrm{Chu}$ et al., 2009a). At $\mathrm{pH} 7$ to 8 , the difference between the formation rate of DCAcAm from DCAN hydrolysis and the hydrolysis rate of DCAcAm was probably higher than that at other $\mathrm{pH}$ levels, as the net yield of DCAcAm was highest at $\mathrm{pH} 7$ to 8 . At $\mathrm{pH} 8$ the maximum formation of $\mathrm{CH}$, similar to that of DCAcAm, was probably due to a larger difference between $\mathrm{CH}$ formation and decomposition at this $\mathrm{pH}$ level. TCNM was relatively stable at pH 5 to 9, in agreement with earlier studies (Joo and Mitch, 2007), and there was no observed effect of $\mathrm{pH}$ on the TCNM yield.

\subsection{Effect of chloramination}

The yields of C- and N-DBPs after a 24-h disinfection of Tyr with different chloramination schemes are summarized in Figures $2 \mathrm{C}$ and $\mathrm{D}$, respectively. The use of chloramines with less free chlorine contact time reduced the yields of the C-DBPs, except 
for 4-CP, which is in agreement with studies with NOM or algae as the precursor (Zhang et al., 2000; Fang et al., 2010). With increasing free chlorine contact time, relatively stable C-DBPs (CF, DCAA, TCAA, and $\mathrm{CH}$ ) increased, whereas 4-CP and N-DBP yields increased and then decreased. Yang et al. (2007) found that a short period (1 to $30 \mathrm{~min}$ ) of chlorination of NOM solutions before switching to chloramination did not form substantial quantities of these DBPs, except for DCAcAm and TCAcAm. A similar phenomenon was some DBP yields were found when the prechlorination time was increased to 1 or $6 \mathrm{~h}$ chloramination schemes, which were chloramination with preformed monochloramine and 
formation of TCAC was tentatively identified (Figure S5). TCAC can react with ammonia to form TCAcAm (Montalbetti and Falque, 2005) (Table S3, Eq. S3). No TCAC was detected during 24-h chlorination or 6-h prechlorination, probably because the TCAC formed was further oxidized by chlorine or hydrolyzed to TCAA (Table S3, Eq. S4).

\subsection{Effect of UV irradiation}

[Fig.3]

A significant increase of the studied DBPs during chlorination after UV exposure was not detected by GC/MS. Moreover,. as shown in Figure S6, the optical spectra of Tyr were similar or slightly larger with UV doses ranging from 19.5 to $585 \mathrm{~mJ} / \mathrm{cm}^{2}$, suggesting that Tyr was relatively unchanged during UV irradiation. Previous studies have shown some structural changes of NOM during UV irradiation, which resulted in an increase in some DBPs (e.g., CF) after UV exposure and subsequent chlorination (Liu et al., 2006; Dotson et al., 2010; Reckhow et al., 2010). However, in another recent study, there was an impact from medium pressure UV whereas there was no impact from low pressure UV (Reckhow et al., 2010), and it was a low pressure system that was used in this study.

The formation of various C- and N-DBPs was evaluated when both UV irradiation and chlorination were conducted at the same time. This resulted in an increase in CF, somewhat of an increase in DCAA and TCAA, and decreases in 4-CP, DCAN, and DCAcAm.

As shown in Table S3, Eq. S5, the DCAN and DCAcAm formation pathway during chlorination was proposed to include substitution, elimination, and decarboxylation reactions, and a further substitution reaction to the methylene group $\left(-\mathrm{CH}_{2}-\right)$ in the main 
chain of an amino acid (Reckhow et al.,2001; Chu et al., 2010b), where $-\mathrm{CH}_{2}$ - is an electron-donating group. The chlorine substitution reaction rate in $-\mathrm{CH}_{2}$ - of Tyr was faster than many other amino acids, probably because of the R- group including an aromatic ring in the side chain of Tyr, which enhanced the electron-donating ability of $-\mathrm{CH}_{2}$ - in the main chain of Tyr (Chu et al., 2010b). The aromatic ring in the R-group was probably broken by a strong oxidizer (e.g., hydroxyl radical, Table S3, Eq. S6) formed under the combined action of UV irradiation and chlorine (Nowell and Hoigne, 1992; Feng et al., 2007), and the extent of the damage to the R-group in the side chain of Tyr increased with increasing UV dose. This probably lessened the electron-donating ability of $-\mathrm{CH}_{2}$ - in the main chain of Tyr and caused the decrease in DCAN and DCAcAm with increasing UV doses. The decrease in 4-CP was also likely caused by the damage of the aromatic ring in the side chain of Tyr. The increase in CF, DCAA, and TCAA could have been caused by the strong oxidizer transforming the Tyr structure to a form that was more reactive with chlorine to form CF, DCAA, and TCAA.

\subsection{Preliminary hypothesis of C- and N-DBPs formation pathways from Tyr}

\section{[Scheme 1]}

A possible integrated pathway of C- and N-DBP formation during Tyr chlorination is proposed in Scheme1. For the reactions A1 to A7, B6, C1 to C6, D1 to D2, and E1 to E4 in Scheme1, the possible formation pathways of DCAN, DCAcAm, DCAA, CH, and TCAN from chlorination of Tyr was modified from previous studies (Reckhow et al., 2001; Joo and Mitch, 2007; Hong et al., 2009; Chu et al., 2010b). From reaction C1 to C10 (secondary reaction), relatively small amounts of CF was formed from further chlorination 
of Ala (Chu et al., 2009b). From reaction B1 to B5 (main reaction), the formation of CF mainly goes through 4-CP, 2,4-dichlorophenol (2,4-DCP), 2,4,6-trichlorophenol (2,4,6-TCP), and a ring opening reaction, which has been confirmed in an earlier study (Chu et al., 2009c). As shown in Figure S7 and Table S5, 4-CP, 2,4-CP, and 2, 4, 6-TCP were formed to much greater extents during chlorination, which was in agreement with above-mentioned results of DBP yields.

Additionally, 4-hydroxyl-benzyl cyanide (4-HBC) during chloramination of Tyr had a high peak (Figure S7), it was likely the main intermediate to form DCAcAm during chloramination by the reactions A1 to A4 (Scheme 1). During chlorination, the formation of DCAcAm was probably from the reactions $E 1, E 2, E 3$, and $A 4$, where benzyl cyanide (Figure S7) was an important intermediate. TCAcAm was less likely to occur from the hydrolysis of TCAN, because TCAN yields were relatively low at all contact times tested. As involved in "3.4. Effect of chloramination", TCAcAm was detected, and TCAC was also identified tentatively, during the same chloramination schemes. A novel possible formation pathway for TCAcAm was proposed; TCAC (Figure S5) could be produced by the ring opening (main reaction B7) and was also probably from chlorination of formaldehyde (secondary reaction C7). Also, it has been well known that TCAC could react quickly with ammonia to yield TCAcAm (reaction C8) (Montalbetti and Falque, 2005). We will confirm the novel possible formation pathway by quantifying TCAC and other intermediates at different experimental conditions in further studies.

\section{Conclusion}



wastewater discharges are important sources of DON in watersheds. Amino acids are precursors to certain C- and N-DBPs. Recent research has indicated that certain emerging DBPs (e.g., HANs, HAcAms, HNMs, haloacetaldehydes) are more toxic than regulated C-DBPs (THMs, HAAs). Thus, it is important to better understand the formation and control of regulated and emerging DBPs. It was found that factors that increased the formation of some by-products of Tyr decreased the formation of others. Moreover, the degradation of some DBPs resulted in the formation of other DBP. The information in this study was used to augment the scheme proposed for the formation of DBPs from Tyr. Increased chlorine dose and $\mathrm{pH}$ could decrease the production of some N-DBPs, but

377 increase the formation of the relatively stable C-DBPs. If a utility had low C-DBP formation potential but was experiencing halogenated N-DBPs (e.g., HAcAms, HANs), it is recommended to try to switch chlorination to chloramination, and chlorine should be dosed after ammonia, based on the results of this study. Meanwhile, it is necessary to concentration and toxic potency could be much greater than these regulated DBPs in certain disinfection conditions 


\section{Acknowledgments}

This project was supported by the national major science and technology project of China (2008ZX07421-002), International Science \& Technology Cooperation Program of China (2010DFA91800), Postdoctoral Science Foundation of China (20110490073) and Shanghai Postdoctoral Sustentation Fund of China (11R21415800). The authors sincerely appreciate comments and revision suggestions from associate editor Prof. Kevin C. Jones (Lancaster University) which improved this manuscript substantially.

\section{References}

Babcock DB, Singer PC. Chlorination and coagulation of humic and fulvic acids. J Am Water Works Assoc 1979; 71: 149-58.

Chu WH, Gao NY, Deng Y. Stability of newfound nitrogenous disinfection by-products: Haloacetamides in drinking water. Chinese J Org Chem 2009a; 29: 1569-74.

Chu WH, Gao NY, Deng Y., Dong BZ. Formation of chloroform during chlorination of alanine in drinking water. Chemosphere 2009b; 77: 1346-51.

Chu WH, Gao NY, Zhao SJ, Deng HP. The mechanism analysis of formation of chloroform during typical dissolved organic nitrogen tyrosine chlorination in drinking water. Acta Chimica Sinica 2009c; 67: 2505-10.

Chu WH, Gao NY, Deng Y. Formation of haloacetamides during chlorination of dissolved organic nitrogen aspartic acid. J Hazard Mater , 2010a; 173: 82-6.

Chu WH, Gao NY, Deng Y, Krasner SW. Precursors of dichloroacetamide, an emerging nitrogenous DBP formed during chlorination or chloramination. Environ Sci Technol 2010b; 44: 3908-12.

Dotson AD, Keen VS, Metz D, Linden KG. UV/ $\mathrm{H}_{2} \mathrm{O}_{2}$ treatment of drinking water increases post-chlorination DBP formation. Water Res 2010; 44: 3703-13.

Fang J, Ma J, Yang X, Shang C. Formation of carbonaceous and nitrogenous disinfection by-products from the chlorination of Microcystis aeruginosa. Water Res 2010; 44: 1934-40.

Feng YG, Smith DW, Bolton JR. Photolysis of aqueous free chlorine species ( $\mathrm{HOCl}$ and $\left.\mathrm{OCl}^{-}\right)$ with 254 nm ultraviolet light. J Environ Eng Sci 2007; 6: 277-84.

Gao NY, Chu WH, Deng Y, Xu B. TCAA degradation in ultraviolet (UV) irradiation/hydrogen peroxide $\left(\mathrm{H}_{2} \mathrm{O}_{2}\right)$ /micro-aeration $(\mathrm{MCA})$ combination process. J Water Supply Res Technol-Aqua 2009; 58: 510-8.

Glezer V, Harris B, Tal N, losefzon B, Lev O. Hydrolysis of haloacetonitriles: Linear free energy relationship, kinetics and products. Water Res 1999; 33: 1939-48. 
Hong $\mathrm{HC}$, Wong $\mathrm{MH}$, Liang $\mathrm{Y}$. Amino acids as precursors of trihalomethane and haloacetic acid formation during chlorination. Arch Environ Contam Toxicol 2009; 56: 638-45.

$\mathrm{Hu}$ J, Song H, Addison JW, Karanfil T. Halonitromethane formation potentials in drinking waters. Water Res 2010; 44: 105-14.

Joo SH, Mitch WA. Nitrile, aldehyde, and halonitroalkane formation during chlorination/chloramination of primary amines. Environ Sci Technol 2007; 41: 1288-96.

Krasner SW, Weinberg HS, Richardson SD, Pastor SJ, Chinn R, Sclimenti MJ, Onstad GD, Thruston AD. Occurrence of a new generation of disinfection byproducts. Environ Sci Technol 2006; 40: 7175-85.

Liu W, Cheung LM, Yang X, Shang C. THM, HAA and CNCl formation from UV irradiation and chlor(am)ination of selected organic waters. Water Res. 2006; 40: 2033-43.

Mitch WA, Krasner SW, Westerhoff P, Dotson A. Occurrence and Formation of Nitrogenous Disinfection By-Products. Denver, Colo: American Water Works Association Research Foundation, 2009.

Montalbetti C, Falque V. Amide bond formation and peptide coupling. Tetrahedron 2005; 61: 10827-52.

Muellner MG, Wagner ED, McCalla K, Richardson SD, Woo YT, Plewa MJ. Haloacetonitriles vs. regulated haloacetic acids: Are nitrogen-containing DBPs more toxic? Environ Sci Technol 2007; 41: 645-51.

$\mathrm{Na} \mathrm{CZ}$, Olson TM. Mechanism and kinetics of cyanogen chloride formation from the chlorination of glycine. Environ Sci Technol 2006; 40: 1469-77.

Nowell LH, Hoigne J. Photolysis of aqueous chlorine at sunlight and ultraviolet wavelengths. I. Degradation rates. Water Res 1992; 26: 593-8.

Plewa MJ, Wagner ED, Jazwierska P, Richardson SD, Chen PH, McKague AB. Halonitromethane drinking water disinfection byproducts: Chemical characterization and mammalian cell cytotoxicity and genotoxicity. Environ Sci Technol 2004; 38: 62-8.

Plewa MJ, Muellner MG, Richardson SD, Fasano F, Buettner KM, Woo YT, McKague AB, Wagner ED. Occurrence, synthesis, and mammalian cell cytotoxicity and genotoxicity of haloacetamides: An emerging class of nitrogenous drinking water disinfection byproducts. Environ Sci Technol 2008; 42: 955-61.

Ram NM. A review of the significance and formation of chlorinated N-organic compounds in water supplies including preliminary studies on the chlorination of alanine, tryptophan, tyrosine, cytosine, and syringic acid. Environ Int 1985; 11: 441-51.

Reckhow DA, Linden KG, Kim J, Shemer H, Makdissy G. Effect of UV treatment on DBP formation. J Am Water Works Assoc 2010; 102: 100-13.

Reckhow DA, Platt TL, MacNeill AL, McClellan JN. Formation and degradation of dichloroacetonitrile in drinking waters. J Water Supply Res Technol-Aqua 2001; 50: 1-13. 
Richardson SD, Plewa MJ, Wagner ED, Schoeny R, DeMarini DM. Occurrence, genotoxicity, and carcinogenicity of regulated and emerging disinfection by-products in drinking water: $\mathrm{A}$ review and roadmap for research. Mutation Res 2007; 636: 178-242.

Richardson SD, Ternes TA. Water analysis: Emerging contaminants and current issues. Anal Chem 2011; 83 4614-48.

Schreiber IM, Mitch WA. Influence of the order of reagent addition on NDMA formation during chloramination. Environ Sci Technol 2009; 39: 3811-8.

Stevens AA, Moore LA, Miltner RJ. Formation and control of non-trihalomethane disinfection by-products. J Am Water Works Assoc 1989; 81: 54-60.

Szajdak L, Österberg R. Amino acids present in humic acids from soils under different cultivations Environ Int 1996; 22: 331-4.

Trehy ML, Bieber TI, 1981. Detection, identification and quantitative analysis of dihaloacetonitriles in chlorinated natural waters, in: Keith LH (Ed.), Advances in the Identification \& Analysis of Organic Pollutants in Water, Vol. 2. Ann Arbor Sci. Publ., Inc., Ann Arbor, Mich., pp. 941-75.

Trehy ML, Yost RA, Miles CJ. Chlorination byproducts of amino acids in natural waters, Environ Sci Technol 1986; 20: 1117-22.

Westerhoff P, Mash H. Dissolved organic nitrogen in drinking water supplies: a review. J Water Supply Res Technol-Aqua 2002; 51: 415-48.

Yang X, Shang C, Westerhoff P. Factors affecting formation of haloacetonitriles, haloketones, chloropicrin and cyanogen halides during chloramination. Water Res 2007; 41: 1193-200.

Zhang XR, Echigo S, Minear RA, Plewa MJ, 2000. Characterization and comparison of disinfection by-products of four major disinfectants, in: Barrett SE, Krasner SW, Amy GL (Eds), Natural Organic Matter and Disinfection By-products: Characterization and Control in Drinking Water. American Chemical Society: Washington, DC, pp. 299-314. 

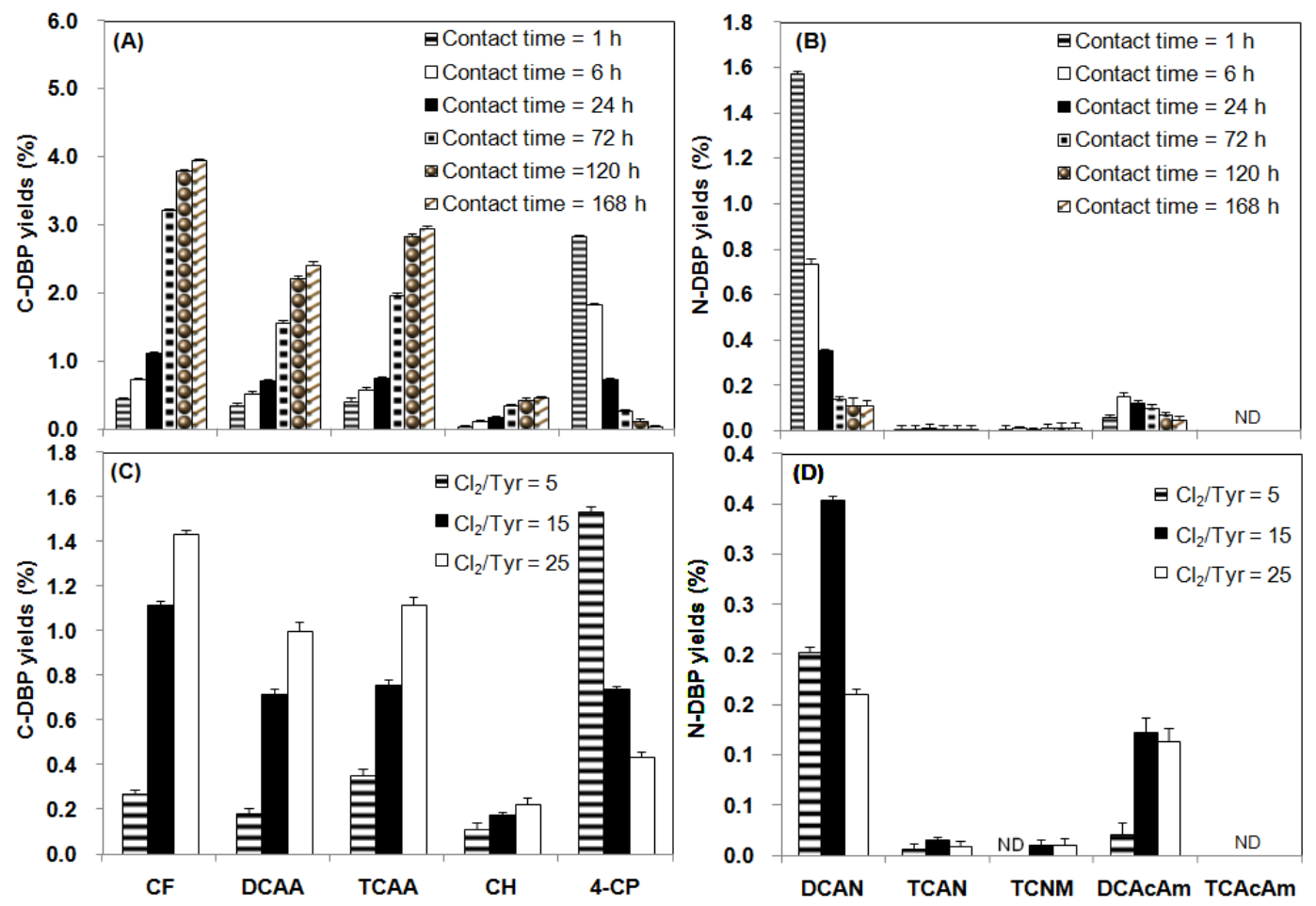

486

487

488

489

490

491

492

493

494

495

496

Fig.1 - Formation of C- and N-DBPs during chlorination of Tyr at different contact times (A and B) and different $\mathrm{Cl}_{2} / \mathrm{Tyr}$ molar ratios $(\mathrm{C}$ and $\mathrm{D})$. Tyr concentration $=0.1 \mathrm{mM}, \mathrm{pH}=7.0 \pm 0.3 . \mathrm{Cl}_{2} / \mathrm{Tyr}=15$ and contact time $=24 \mathrm{~h}$, except as noted. The bars represent the standard deviation of replicate measurements $(n=3)$. 

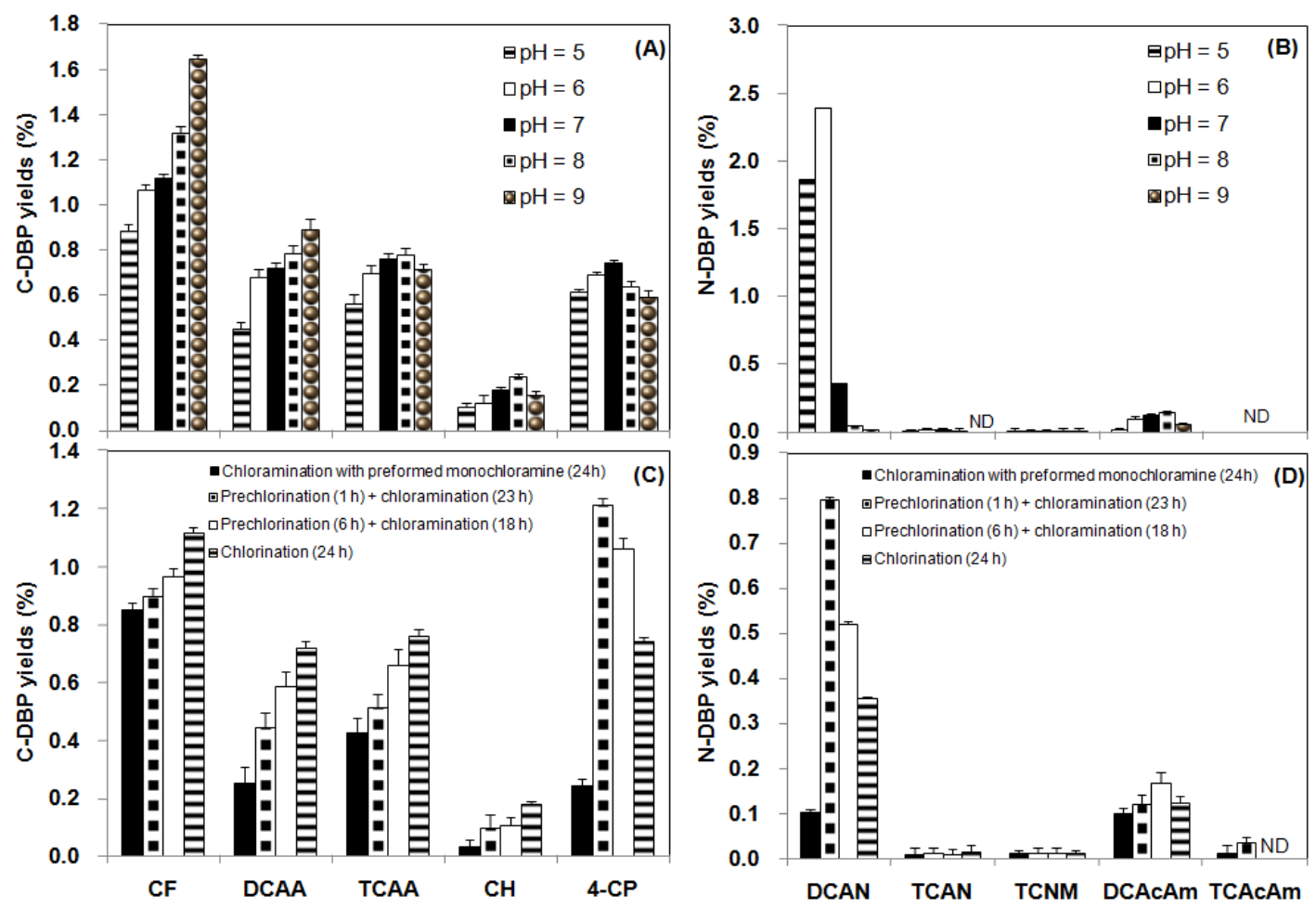

Fig.2 - Formation of C- and N-DBPs during chlorination of Tyr at different pH levels (A and $B$ ) and chloramination schemes $(C$ and $D)$. Tyr concentration $=0.1 \mathrm{mM}$, total disinfectant contact time = $24 \mathrm{~h}, \mathrm{pH}=7.0, \mathrm{Cl}_{2} / \mathrm{Tyr}=15$, and $\mathrm{Cl}_{2} /$ ammonia = 1, except as noted. The bars represent the standard deviation of replicate measurements $(n=3)$. 

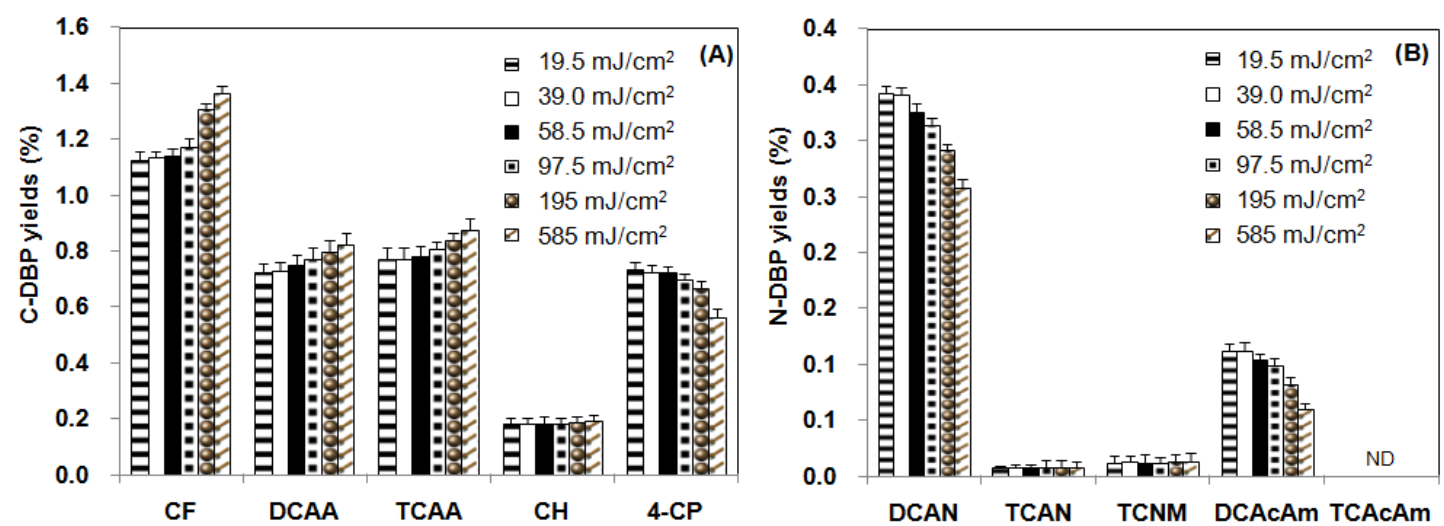

Fig.3 - Formation of C- and N-DBPs at different UV dosages (UV irradiation and chlorination were

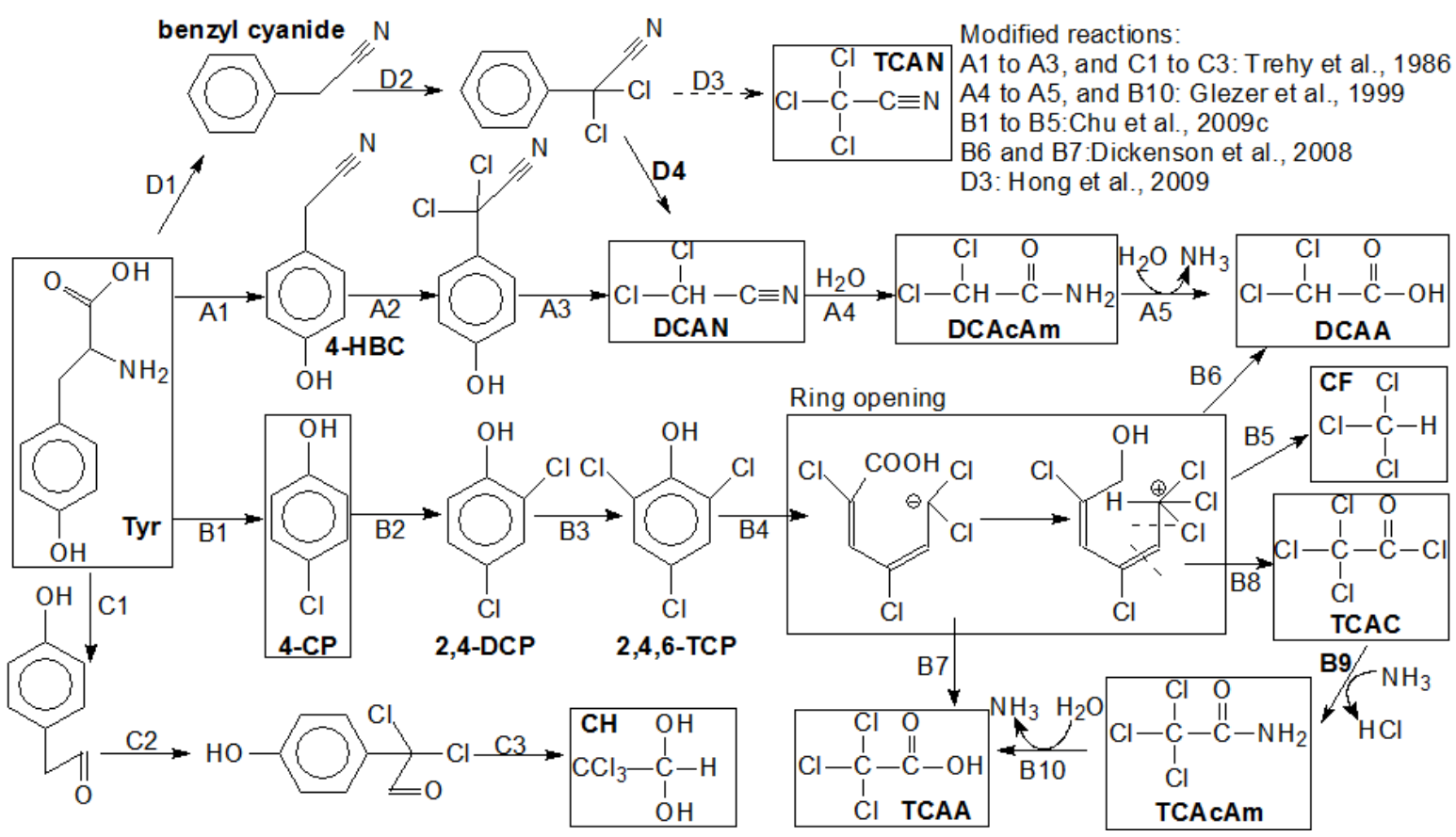

